\title{
Cell proliferation and tumor formation induced by eserine, an acetylcholinesterase inhibitor, in rat mammary gland
}

\author{
G.M. CALAF ${ }^{1,2,3}$, E. PARRA ${ }^{4}$ and F. GARRIDO ${ }^{5}$ \\ ${ }^{1}$ Center for Radiological Research, Columbia University Medical Center, New York, NY, USA; \\ ${ }^{2}$ Institute for Advanced Research, and ${ }^{3}$ Research Center for the Man in the Desert, Tarapacá University, Arica; \\ ${ }^{4}$ Laboratory of Signal Transduction and Gene Therapy, Disciplinary Program of Pharmacology, ICBM, \\ Faculty of Medicine, and ${ }^{5}$ Institute of Nutrition and Food Technology, University of Chile, Santiago, Chile
}

Received July 11, 2006; Accepted September 21, 2006

\begin{abstract}
Environmental chemicals may be involved in the etiology of breast cancer. There is substantial evidence that breast cancer risk is associated with prolonged exposure to female hormones. Among these hormonal influences a leading role is attributed to the ovarian hormone estradiol, since breast cancer does not develop in the absence of ovaries. The rat mammary gland has special characteristics that make it an ideal organ for studying development, cell proliferation and transformation. In vivo and in vitro model systems for cell proliferation and mammary carcinogenesis have allowed morphological and biochemical analysis under different experimental conditions. The aim of this study was to examine the effect of eserine, an acetylcholinesterase inhibitor, as are the organophosphorous compounds malathion and parathion, and $17 ß$ estradiol on cell proliferation and tumor formation that takes place in the rat mammary gland after in vivo and in vitro treatment. These studies showed that eserine and $17 ß$ estradiol were capable of inducing carcinogenesis in the epithelium of rat mammary glands. It was found that there was a significant increase in the number of cells per duct of the 44-day-old rat mammary gland after the 10-day eserine treatment, compared to the control. A higher increase was observed in the animals treated for 10 days with eserine followed by 30 -daily injections of estrogen in comparison to control animals. In 12 animals, two mammary tumors were directly developed in response to $17 ß$ estradiol injected at 39 days of age with a latency period of 180 and 245 days, respectively. Such tumors were metastatic to the lung. These results suggest that terminal end buds are major targets related to rat mammary carcinogenesis and $17 ß$ estradiol can be an initiator and promoter in this process.
\end{abstract}

Correspondence to: Dr Gloria M. Calaf, Institute for Advanced Research, Research Center for the Man in the Desert, Campus Velasquez, Tarapacá University, Arica, Velasquez 1775, Chile E-mail: gmc24@columbia.edu

Key words: eserine, acetylcholinesterase inhibitor, mammary gland

\section{Introduction}

Environmental pollutants may be involved in the etiology of breast cancers because the majority of all human tumors can be attributed to external environmental factors such as tobacco smoke, dietary constituents (additives), pollutants, drugs and pesticides, in conjunction with both genetic and acquired susceptibility (1). On the other hand, breast cancer is the most frequent malignancy in a hormone-regulated organ and there is much evidence that breast cancer risk is associated with prolonged exposure to naturally occurring female hormones. Early onset of menarche, late menopause, hormone replacement therapy and postmenopausal obesity are associated with greater incidence of cancer (2-5). Among these hormonal influences the estradiol from ovarian or extra-ovarian origin is considered a major contributor since breast cancer does not develop in the absence of ovaries. The removal of the ovaries can cause the regression of established malignancies, and in experimental animal models estrogens can induce mammary cancer (6).

Eserine [(3,S-cis)-1, 2, 3, 3, 8, 8 -Hexahydro-1, 3, 8trimethylpyrrolo (2,3-b) indol-5-ol methylcarbamate] is an acetylcholinesterase inhibitor, as are the organophosphorous compounds malathion and parathion. It is an ester obtained from the Calabar Bean, the seeds of the vine Physostigma venenosum. It is used as a miotic drug and for the atony of gastrointestinal tract, but it is very toxic if directly inhaled or swallowed. Eserine is incorporated through the epithelium of the skin, mouth, and respiratory tract. It is responsible for the hydrolysis of choline esters found in the body, including the acetylcholine present at cholinergic synapse (7-9). The inhibition of acetylcholinesterase increases the availability of acetylcholine, which in turn can stimulate cholinergic receptors producing both nicotinic and muscarinic effects in the organism such as muscle contractions and secretions in many glands (8).

The rat mammary gland is an organ with characteristics that make it ideal for studying the development, cell proliferation and transformation of cancer. It has been shown that cell proliferation in the rat mammary gland occurs in a non-random fashion since specific compartments react with varied rates of proliferation $(10,11)$. The structure of a normal rat mammary gland is composed of a single primary or main lactiferous 
duct that branches into secondary ducts at birth and during the first week of postnatal life. During the second week, further sprouting of ducts occurs up to the sixth cell generation. This sprouting of ducts causes a marked increase in the density of terminal end buds (TEBs), which reach their maximum magnitude when the animal is 21-days old (10). Such structures are narrow and straight and end in small, club-shaped terminal structures composed of three to six layers of medium-sized epithelial cells from which numerous TEBs begin to differentiate and cleave into smaller alveolar buds $(\mathrm{ABs})$ from which lobules are formed $(10,11)$. The differentiation of the mammary gland induces a progressive decrease in the number of TEBs and a concomitant increase in the number of ABs.

Models to study mammary carcinogenesis have been developed with the chemical carcinogen, dimethylbenz $[a]$ anthracene, in Sprague-Dawley rats (12). Such substances induced mammary carcinomas in $100 \%$ of the animals with a latency period of 86 days. Another study also reported neoplastic transformation of epithelial cells by the effect of a single administration of $\mathrm{N}$-methyl-N-nitrosourea (NMU) in mammary glands in vivo (13). Another widely used experimental system to study mammary cancer has been one induced by NMU in Fischer 344 rats (14). The administration of DMBA to virgin rats of different ages induced tumors with an incidence that was directly proportional to the density of highly proliferating TEBs (10).

To study cell proliferation of mammary glands we need in vitro systems that allow the study of morphological and biochemical parameters under different experimental conditions. In vitro model systems have been extensively used to study the processes of initiation, progression and metastasis. Several authors have developed models to study these processes (15-25). Most of them give a unique opportunity for studying mammary gland changes that can occur by the effect of different exogenous and endogenous substances. Recently, it has become possible to make the culture environment closer to that found in vivo. Structures of the mammary gland, such as TEBs and ABs, can be separated from mesenchyme by enzymatic digestion and then filtered through a controlled pore size (26). The aim of this study was to examine the effect of eserine sulfate (eserine) followed by $17 ß$ estradiol (estrogen) on cell proliferation and tumor formation that takes place in the rat mammary gland after in vivo and in vitro treatment.

\section{Materials and methods}

Isolation of rat mammary gland structures for cell proliferation in vitro studies. Female nulliparaous Sprague-Dawley rats were obtained from the Metropolitan University at Santiago, Chile. Animals were housed and bred in a barrier animal facility operated in accordance with the standards outlined in Guide for the Care and Use of Laboratory Animals (27). All animals were allowed continuous access to a standard laboratory diet (Champion, Santiago, Chile). The first set of experiments was performed to isolate the mammary gland structures of virgin female rats of 21 and 44 days of age. Four groups of five animals each were injected twice a day subcutaneously for 10 days in the inguinal region of the body. Control animals were injected twice with saline solution and experimental animals with eserine (300 $\mu \mathrm{g} / 100 \mathrm{~g}$ body weight) (bw) (Sigma, St. Louis MO). Mammary glands were removed and processed by enzymatic digestion studies to measure TEBs and ABs yielded in the media. The mammary gland tissue was washed with serum-free media (approximately $10 \mathrm{ml}$ ) four times and the wash solution was discarded. The mammary gland tissue was cut in $10 \mathrm{ml}$ wash solution and digested with Type IV collagenase $(250 \mathrm{U} / \mathrm{ml})$, hyaluronidase $(100 \mathrm{U} / \mathrm{ml}), 10 \%$ fetal calf serum and fungizone $(0.25 \mu \mathrm{g} / \mathrm{ml})$ in medium RPMI. The tissue was digested at $37^{\circ} \mathrm{C}$ for $6-24 \mathrm{~h}$ with constant rotator shaking at $80 \mathrm{rpm}$ to yield a suspension of intact structures that were counted in a Thomas camera to obtain a specific density, expressed as structures per $\mathrm{ml}$. Then tissue was passed through 90 - to $200-\mu \mathrm{m}$ filters and washed for $2 \mathrm{~h}$ to obtain clean structures. Such structures were TEBs (90- $\mu \mathrm{m}$ filters) and ABs (200- $\mu$ m filters).

Cell proliferation and transformation. Part of the enzymatically digested tissue was filtered though $50-\mu \mathrm{m}$ filters and then centrifuged at $1200 \times \mathrm{g}$ for $10 \mathrm{~min}$ and washed for $2 \mathrm{~h}$ to obtain isolated epithelial cells. The digested tissues were checked by inverted microscope. After 14 days in culture, the digestion of cells derived from TEBs and ABs was used to determine cell proliferation, by counting the number of cells per dish and anchorage independent growth. The media was enriched with insulin $(5 \mu \mathrm{g} / \mathrm{ml})$ and corticosterone $(1 \mu \mathrm{g} / \mathrm{ml})$ in the different experiments.

Anchorage independence. An anchorage independent assay was used to test for cell growth in a semisolid medium. Cells from 14-day cell cultures of TEBs and ABs isolated from virgin female control and eserine-treated rats of 44 days of age were trypsinized and replated in DMEM/F-12 medium containing $10 \%$ bovine serum plus $1.2 \%$ methocel. Control and treated cells were plated in 24 multi-well plates of which the bottoms were precoated with an agar layer prepared by adding $5 \%$ agar to DMEM/F-12 (2X) medium to give a final agar concentration of $0.9 \%$. Cells were seeded in $0.8 \%$ methylcellulose at a concentration of $1 \times 10^{4}$ cells/well. After 3 weeks of incubation, colonies were counted to determine colony number (24).

The second set of experiments was performed to study the cell proliferation of isolated structures of the mammary glands of 10 virgin female rats of 44 days of age to measure DNA synthesis. Two groups of five animals each were injected twice a day subcutaneously for 10 days in the inguinal region of the body. Control animals were injected with saline solution and experimental animals with eserine $(300 \mu \mathrm{g} / 100 \mathrm{~g}$ bw) (Sigma, St. Louis MO). The DNA synthesis was studied by injecting ${ }^{3} \mathrm{H}$ methyl thymidine (specific activity $20 \mu \mathrm{C} / \mu \mathrm{mol}$, Du Pont New England Nuclear Products, Boston, MA) $18 \mathrm{~h}$ after the last eserine injection at a concentration of $10.0 \mu \mathrm{Ci} / \mathrm{ml}$. The animals were sacrificed $5 \mathrm{~h}$ after injection. The specific activity, that is $\left[{ }^{3} \mathrm{H}\right]$-thymidine incorporation into DNA, was measured in cells derived from TEBs from both control and eserine-treated animals, each cultured for 5-days. There was no lobule formation in such animals. DNA synthesis was performed as previously reported $(28,29)$.

Histomorphometric analysis in rat mammary glands from in vivo studies. The first in vivo experiment was performed to 

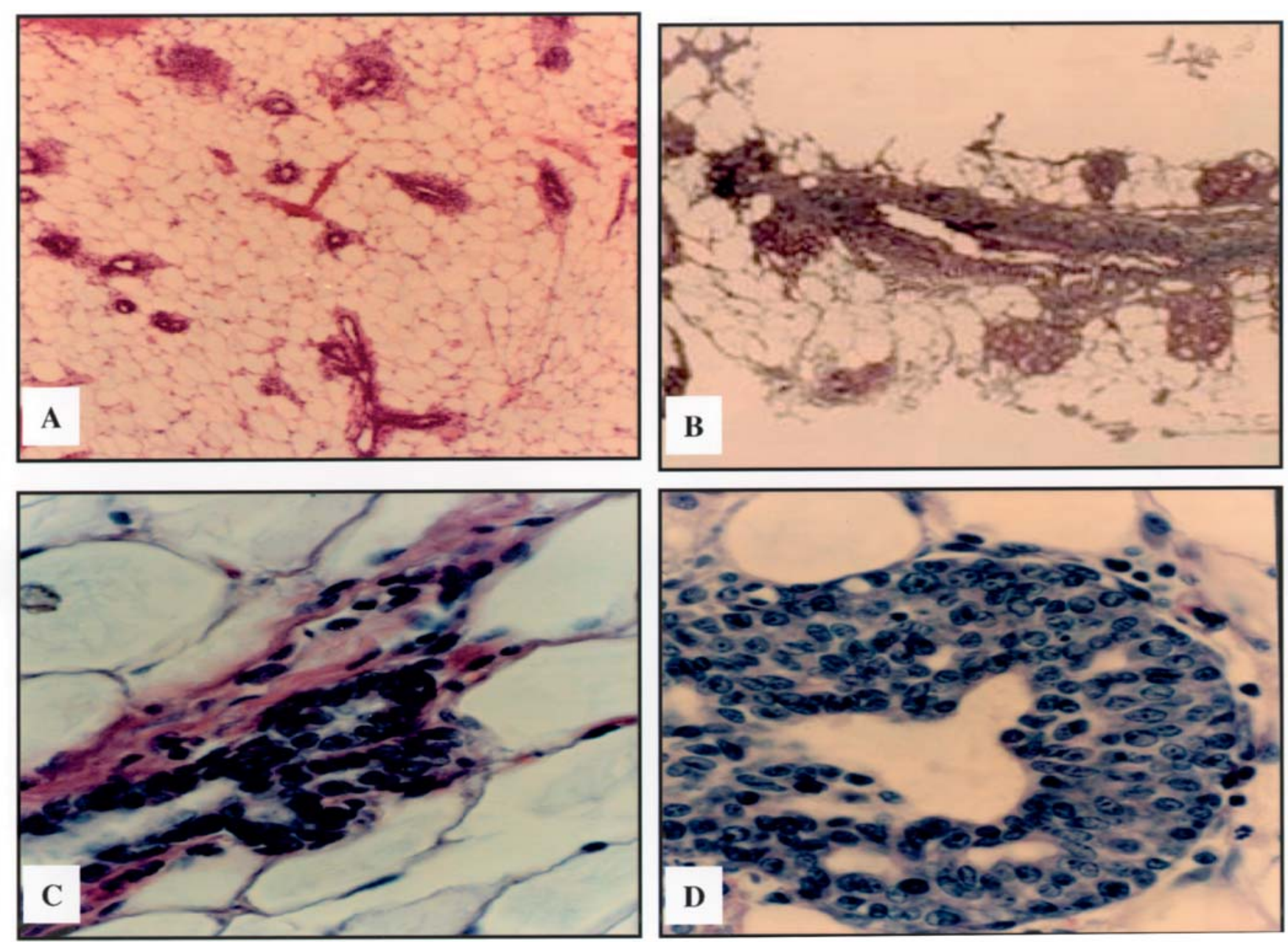

Figure 1. (A) Histological section of 21-day-old female rat mammary gland; only TEBs are present (x350). (B) Structures of mammary gland from the control 44-day-old rat composed of a main lactiferous duct, which is beginning to cleave into ABs forming lobules (x400). (C) Histological section of small alveolar bud (x350) found in 21-day-old eserine-treated rat mammary gland. (D) Histological section of a TEB from 44-day-old eserine-treated rat mammary gland (x400); hematoxylin and eosin.

count the number of cells per structure by the effect of eserine. Five 44-day-old control virgin female rats were injected subcutaneously for 10 days twice a day with physiological saline solution $(100 \mu \mathrm{g} / 100 \mathrm{~g}$ bw) and five with eserine (300 $\mu \mathrm{g} / 100 \mathrm{~g} \mathrm{bw})$. The animals were sacrificed on the day following the last injection and the mammary glands were removed and histologically analyzed. Rat mammary glands were fixed in Bouin's fixative and embedded in paraffin. The glands were oriented flat and serially sectioned at a thickness of $5 \mu \mathrm{m}$ and stained with hematoxylin and eosin. Histomorphometry, an analysis of cellular structure, was performed using a Baush and Lomb (Rochester, NY, USA) binocular microscope, in which a $1-\mathrm{mm}^{2}$ grid was installed in one of the oculars. The measurements were performed with a $\times 10$ ocular. Five slides per animal were counted to determine the number of cells, ducts, alveoli, and lobules in the mammary gland of control and treated animals. Mammary gland cell proliferation was determined by counting the number of lobules per duct, alveoli per lobule and cells per duct.

The second in vivo experiment was performed by counting the number of cells per structure affected by eserine for 10 days followed by estrogen for 30 days. There were 3 groups of 44-day-old rats: a) 7 control rats were injected twice daily for
40 days with physiological saline solution $(100 \mu \mathrm{g} / 100 \mathrm{~g} \mathrm{bw})$; b) 7 experimental animals were injected with eserine $(300 \mu \mathrm{g} /$ $100 \mathrm{~g} \mathrm{bw})$ daily for 40 days; c) 7 animals were treated with eserine twice a day for 10 days followed by estrogen for 30 days $(200 \mu \mathrm{g} / 100 \mathrm{~g} \mathrm{bw})$ once a day. At the end of this period the animals were sacrificed and the rat mammary gland histology was analyzed and cell proliferation was determined by counting the number of lobules per duct, alveoli per lobule and cells per duct. A total of 20 areas of $1 \mathrm{~mm}^{2}$ were counted in each gland. The data are expressed as the average \pm standard error (SE) of the mean. Thirty cells/field were counted in 15 randomly selected microscope fields (x400) per sample. All numerical data were calculated as means and error standards. Comparison between treated groups and controls was made by Student's t-test. A p value of $\leq 0.05$ between groups was considered to be significant.

The third in vivo experiment was performed to detect the effect of $17 \AA$ estradiol alone on cell proliferation. One group of twelve 39-day-old rats was injected subcutaneously with $17 ß$ estradiol (300 $\mu \mathrm{g} / 100 \mathrm{~g} \mathrm{bw}$ ) (Sigma, St. Louis MO) in the inguinal region of the body, twice a day for 5 days. Another group of twelve 39-day-old rats was injected subcutaneously with saline solution $(100 \mu \mathrm{g} / 100 \mathrm{~g} \mathrm{bw})$ in the inguinal region 

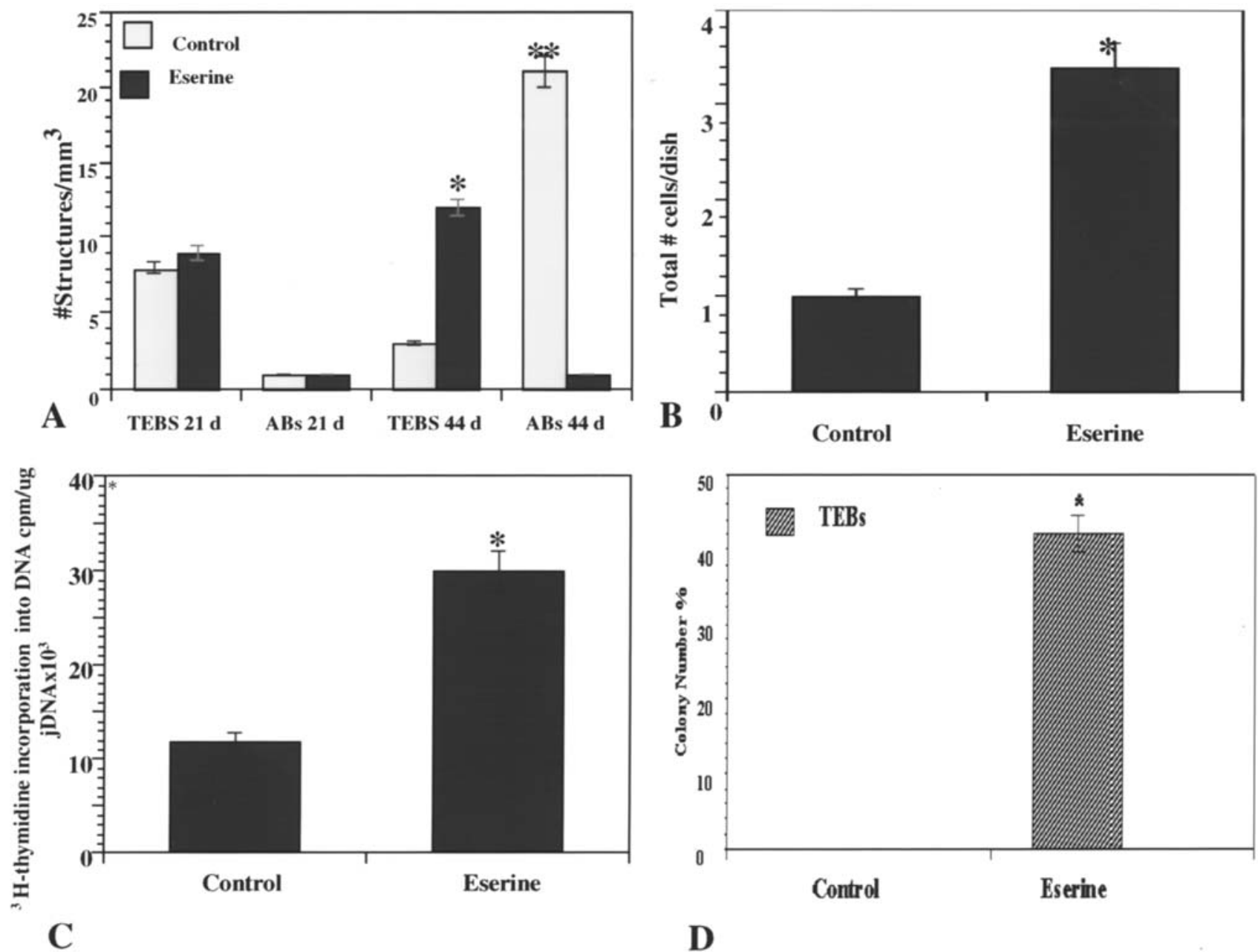

Figure 2. (A) The bars represent the mean \pm SE, $n=5$, of the effect of eserine treatment on no. of structures isolated from 21- and 44-day-old rat mammary gland. Structures were isolated from animals treated with eserine in vivo for 10 days. Control versus eserine rats (21 days old): non-significant difference in density between either TEBs or ABs. Eserine versus control rats (44 days old): density of TEBs, ${ }^{*}$ p $<0.05$. Eserine versus control rats (44 days old): density of $\mathrm{ABs},{ }^{* *} \mathrm{p}<0.01$. (B) The bars represent the mean $\pm \mathrm{SE}, \mathrm{n}=5$, of total no. of cells per dish isolated from TEBs from 44-day-old eserine-treated rat mammary gland in comparison to control: TEBs, ${ }^{*} \mathrm{p}<0.05$ versus control. (C) The bars represent the mean $\pm \mathrm{SE}$, $\mathrm{n}=5$, of the effect of eserine on $\left[{ }^{3} \mathrm{H}\right]$-thymidine incorporation into DNA (cpm x $10^{3}$ ) of 44-day-old rat mammary gland. TEBs, ${ }^{*} \mathrm{p}<0.05$ versus control. (D) The bars represent the mean $\pm \mathrm{SE}$, $\mathrm{n}=5$, of colony formation $(\%)$ from cells isolated from TEBs of 44 -day-old eserine-treated rat mammary gland: TEBs, ${ }^{*}$ p $<0.05$ versus control. Cells from TEBs were previously cultured for 14 days.

of the body for 5 days. All the animals were housed three per cage for 10 months and were palpated weekly to detect formation of tumors. Palpable tumors were removed from the animals after one month of detection. At the end of the 10-month observation period, the animals were sacrificed under ether anesthesia and opened by a midline incision from the pubis to the submaxillary area to remove several organs to look for tumor formation. Tumors were fixed in Bouin's fluid, and embedded in paraffin. The blocks were sectioned at a thickness of $5 \mu \mathrm{m}$. Deparaffinized sections were stained with hemotoxylin and eosin and the tumors were analyzed under the microscope.

\section{Results}

These studies showed that eserine, an acetylcholinesterase inhibitor, is capable of transforming the epithelium of rat mammary gland and that estrogen is a promoting factor as well as an initiator in rat mammary cancer carcinogenesis.
The 21-day-old rat mammary gland consists mainly of TEBs. Fig. 1A shows the histological section of the mammary gland tissue of a 21-day-old female control rat. There are numerous TEBs but no ABs present at this age. A normal rat mammary gland is composed of main lactiferous ducts that cleave into ABs. In the histologic section of a control 44-day-old rat mammary gland the structures of a normal rat mammary gland can be seen: a main lactiferous duct that was cleaved into $\mathrm{ABs}$ and that has evolved into lobules (Fig. 1B). Eserine induced a significant increase in the number of TEBs after 10-day treatment. Representative images of an alveolar bud (Fig. 1C), which were almost absent, and TEB (Fig. 1D) from an eserine-treated 21-day-old rat are shown. There were no ABs present in these animals. A representative TEB of a 44-day-old eserine-treated rat, where TEBs were prominent in size, is shown in Fig. 1D.

Enzymatic digestion of rat mammary gland to obtain the TEB and $A B$ structures isolated from animals treated with eserine in vivo for 10 days showed that there was no significant 

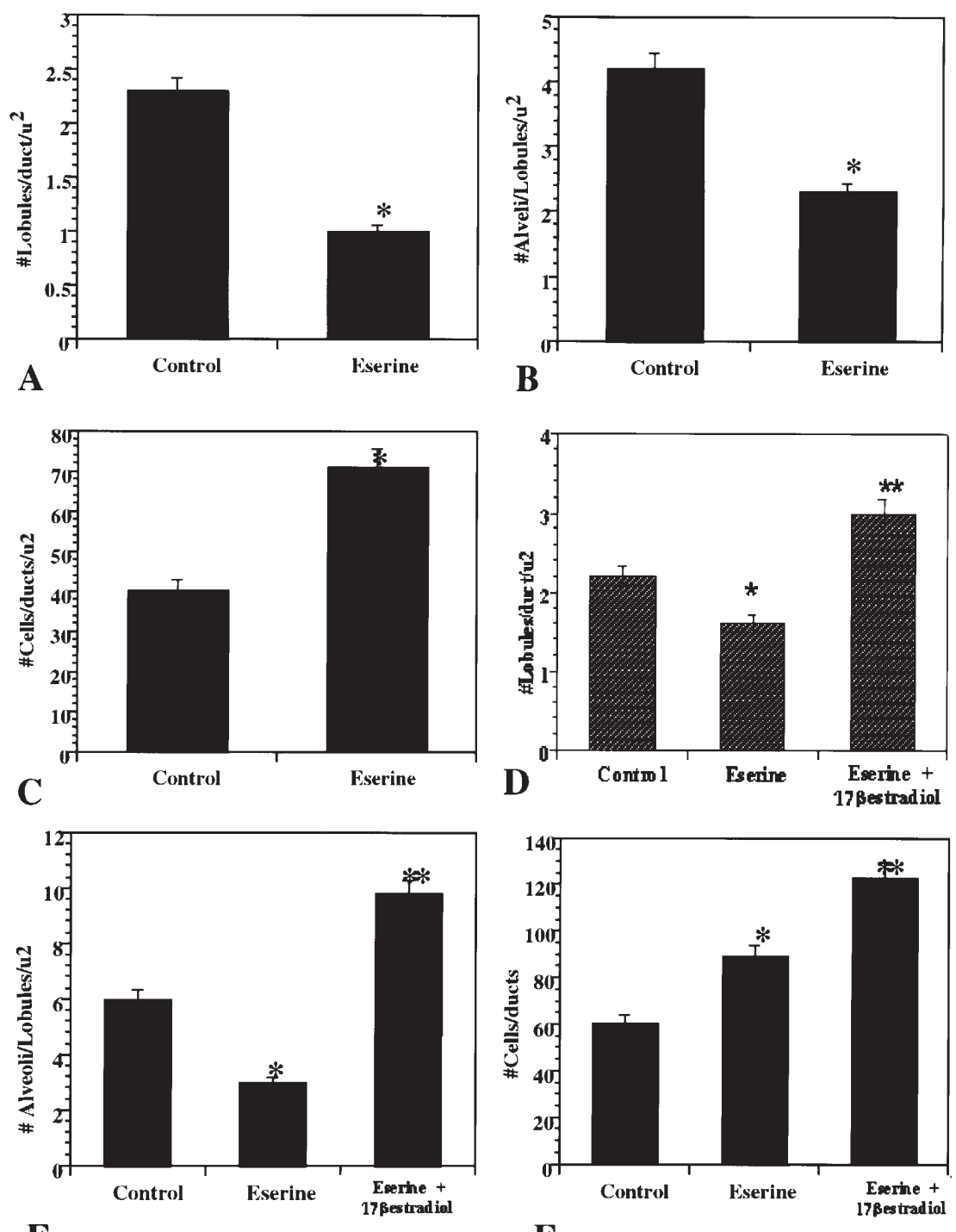

$\mathbf{E}$

$\mathbf{F}$

Figures 3. (A-C) The bars represent the mean \pm SE of the effect of eserine on the no. of lobules per ducts (A), alveoli per lobules (B) and cells per duct (C) found in histological section of 44-day-old eserine-treated rat mammary gland after 10 days of eserine treatment. TEBs, ${ }^{*} \mathrm{p}<0.05$ versus control. (D-F) The bars represent the mean \pm SE of the no. of lobules per ducts (D), alveoli per lobule (E) and cells per duct (F) found in histological section of 44-day-old rat mammary gland after 10 days of eserine treatment followed by 30 days of $17 ß$ estradiol treatment. ${ }^{*} \mathrm{p}<0.05$, eserine versus control. ${ }^{* *} \mathrm{p}<0.05$, eserine + estrogen versus control.

difference in the density of TEBs and ABs between 21-dayold control and eserine-treated animals (Fig. 2A). However, enzymatic digestion of a 44-day-old rat mammary gland yielded a significant $(p<0.05)$ greater density of TEBs in the eserine-treated animals in comparison to control. There was a significant $(p<0.01)$ decrease in the density of $A B s$ in the eserine-treated animals. The number of ABs was significantly $(\mathrm{p}<0.01)$ greater than the TEBs in the control groups. Bars in Fig. 2A represent the mean $\pm \mathrm{SE}$ of the effect of eserine treatment on the number of structures isolated from 21- and 44-day-old rat mammary glands after 10-day treatment.

Further enzymatic digestion of TEBs and ABs from 44day-old rat mammary gland yielded isolated cells in control and eserine-treated groups. Quantification of the total number of cells per dish of 14-day cultures derived from control and eserine-treated animals is presented in Fig. 2B. Cells from ABs did not grow under these conditions. However, cells derived from TEBs from eserine-treated animals significantly $(p<0.05)$ increased in number in comparison to control. Determination of DNA synthesis is shown in Fig. 2C. Results indicated that $\left[{ }^{3} \mathrm{H}\right]$-thymidine incorporation into DNA was significantly $(p<0.05)$ higher in cells derived from TEBs from treated animals than from control animals. An anchorage independent assay was performed with cells derived from TEBs and ABs from 44-day-old animals treated with eserine. There was no formation of colonies in cultures with cells derived either from TEBs and ABs from the control group (Fig. 2D), or from ABs from the experimental group. However, cells derived from TEBs induced $43 \%$ colony formation in the presence of eserine.

Fig. 3A shows the effect of 10-day eserine treatment on cell proliferation in mammary gland tissue of 44-day-old rats. Histomorphometric analysis indicated that control rats had normal lobule formation. However, there was no $\mathrm{AB}$ formation in the eserine-treated animals. A significant $(p<0.05)$ decrease in the number of lobules per duct and alveoli per lobule after 

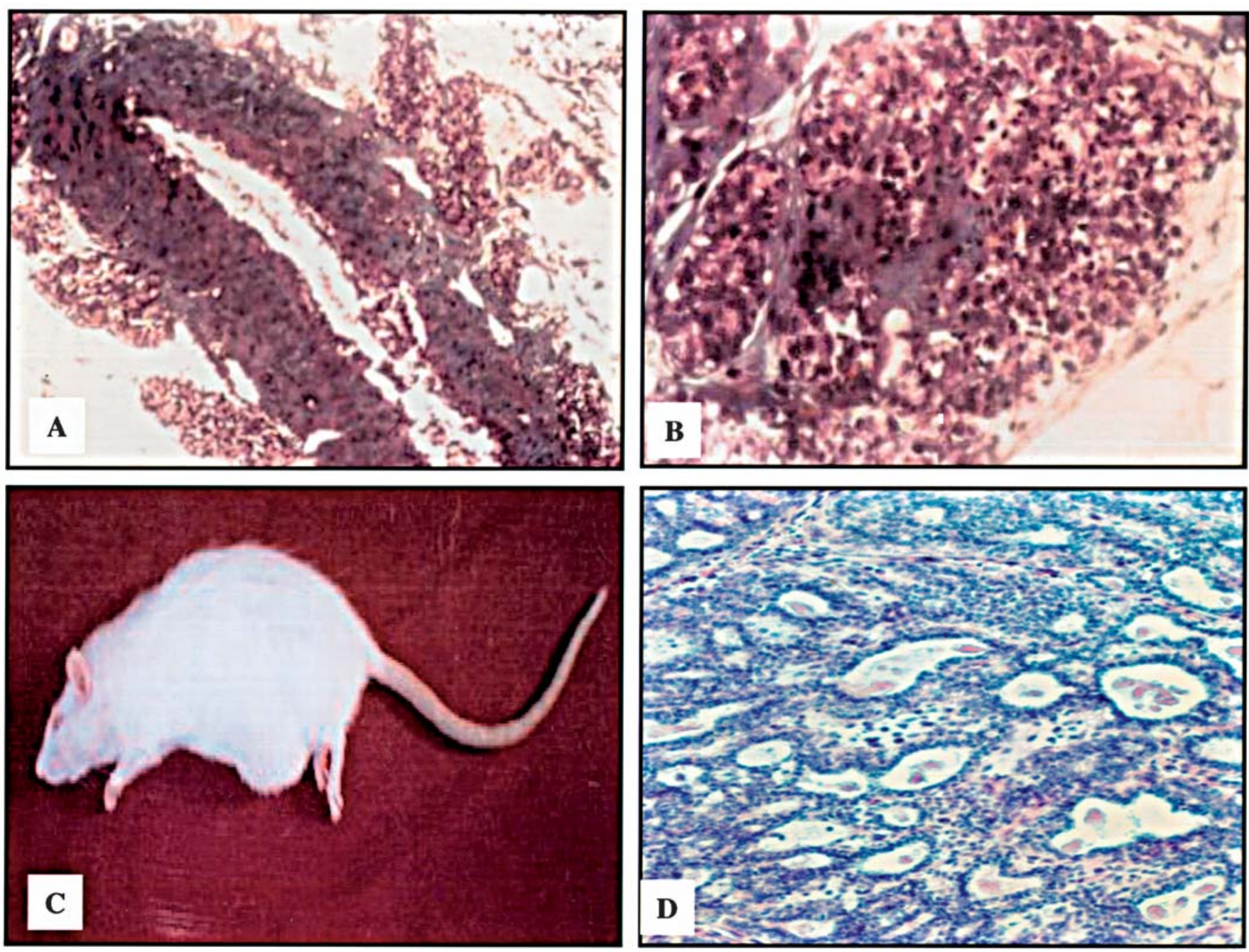

Figure 4. (A) Structures of the mammary gland from the 44-day-old rat administered eserine followed by estrogen: the proliferative characteristics of ABs and main duct are appreciated (x350). (B) Histological section of one AB (x400). (C) Mammary tumor developed in the mammary gland region by the effect of $17 B$ estradiol treatment of 44-day-old female rat. (D) Cross-section of a tumor derived from such an animal, papillary adenocarcinoma type, grossly nodular and encapsulated (x400); hematoxylin and eosin.

10 days of eserine treatment was found in comparison to controls as seen in Fig. 3A and B, respectively. However, there was a $(\mathrm{p}<0.05)$ significant increase in the number of cells per duct in the eserine-treated animals in comparison to the control (Fig. 3C). Histomorphometric analysis was performed in histological sections of 44-day-old rat mammary glands to analyze the effect of 10-day eserine treatment followed by injections of estrogen for 30 days. Fig. 3D and E shows the effect of eserine on the number of lobules per duct, alveoli per lobule and cells per duct, respectively. Results showed that there was a significant $(\mathrm{p}<0.05)$ decrease in the number of lobules per duct (Fig. 3D) and alveoli per lobule (Fig. 3E) after 40-day eserine treatment. However, there was a significant $(\mathrm{p}<0.05)$ increase in the number of cells per duct in the eserine followed by estrogen treatment in comparison to control and eserine groups (Fig. 3F). A representative image of $\mathrm{ABs}$ of prominent size, of eserine followed by estrogen treatment 44-day-old animals can be seen in Fig. 4A. Fig. 4B is a higher magnification of the proliferative ducts found in Fig. 4A. During the 10-month period of observation of 173 estradiol-treated animals it was found that two out of 12 animals developed mammary tumors. Such tumors were localized in the abdominal region (Fig. 4C). The sizes varied between 30 and $39 \mathrm{~cm}^{3}$ with a latency of 180 and 245 days, respectively. The histological analysis revealed that these tumors were adenocarcinomas, grossly nodular and encapsulated with abnormal epithelial cell growth (Fig. 4D).

\section{Discussion}

The susceptibility of the mammary gland to malignant transformation has been related to its degree of development and proliferative activity (10). It has been shown that the high susceptibility of the TEBs to malignant transformation is attributed to the kinetic cell properties of the epithelium of the rat mammary gland. Understanding the process of carcinogenesis can be achieved by using adequate in vivo and in vitro model systems. This study aimed to determine the effect of eserine and estrogen on cell proliferation of the epithelium of mammary gland in rats of 21 and 44 days of age. Cell proliferation in the mammary gland relates significantly to age and hormones levels. In the lifespan of the rat the highest concentration of TEBs is found at 21 days of age. The main regulating factor in the TEB development is the 
secretion of ovarian and placental hormones, which in their sequential appearance stimulate these structures to proliferate and cleave into $\mathrm{ABs}$ that evolve into secretary lobules of the lactating breast. The present study indicates that mammary gland structures isolated by enzymatic digestion from 21-dayold animals showed no significant difference in the density of TEBs and ABs in the 10-day eserine-treated animals in comparison to controls. However, there was greater density of TEBs in the 10-day eserine-treated rats in comparison to controls of 44-day-old animals. The number of ABs was significantly greater than TEBs in the 44-day-old control rats. This observation suggested that, as seen as in the control animals, eserine inhibited the normal process of differentiation from TEBs to ABs. These important observations corroborate that those structures which are considered equivalent to the terminal ductal lobular unit described in the human breast, are critical in mammary cancer $(10,11)$. We have previously reported that eserine, an acetylcholinesterase inhibitor, as are organophosphorous pesticides, induced tumor formation in a specific target organ, such as the mammary gland (30).

Cells isolated by enzymatic digestion derived from 44day-old eserine-treated animals significantly increased in number and DNA synthesis in TEBs cultured for 14 days in comparison to control, after 5 days in culture. ABs did not grow under these conditions. Reports have shown that DNA-LI among young virgin rats was much higher than among old virgin rats $(10,11)$. The TEBs of young virgin rats had a cell cycle of an average length of $11 \mathrm{~h}$, lengthening to 21 and $28 \mathrm{~h}$ in the terminal ducts and ABs, respectively. Cell kinetic parameters varied among the different compartments of the breast in the human female and were affected by age and gland topography (31).

Samples of normal human breast tissue were previously studied in organ culture systems (32-35). Such results indicated important differences among the mammary glands of young and old women $(32,33)$. DNA synthesis was higher in the intralobular terminal ducts and lower in alveoli and main ducts. The high rate of cell proliferation was associated with the shortened length of the cell cycle. The length of the cell cycle in these structures increased from 200.3 to $847.0 \mathrm{~h}$ in the older women (31). The effects of the early years of a woman's life have a significant influence on the process of carcinogenesis. Breast tissue seems to be very sensitive to ionizing radiation when exposure occurs between the ages of 15 and 19 years (36).

An anchorage independent assay was performed with cells derived from TEBs of ABs of 44-day-old animals. Cells derived from TEBs of the eserine-treated group induced colony formation. However, ABs did not form any colony. These results suggest that cells were transformed by the eserine treatment, corroborating other studies where this assay has been used for this purpose $(20,24)$. These results are in agreement with previous reports that acquisition of anchorageindependent growth is considered one of the most frequent phenotypic alterations in carcinogen-exposed or oncogenetransfected mammary cells $(37,38)$.

Histological examination of mammary tissue of 44-dayold rats showed that control rats had normal lobule formation. However, there were no ABs in the 44-day-old eserine-treated animals. Furthermore, a significant decrease in the number of lobules per duct and number of alveoli per lobule was found after 10 days of in vivo eserine treatment as well as 10-day eserine treatment followed by 30 daily injections of estrogen in comparison to control. Interestingly, there was a significant increase in the number of cells per duct of 44-day-old rat mammary gland in the 10-day eserine treatment and 10-day eserine treatment followed by 30 daily injections of estrogen animals in comparison to control. These results suggest that ducts are the structures related with cell transformation in this model.

Eserine and estrogens, as well as organophosphorous pesticides malathion and parathion, seem to act on undifferentiated structures, TEBs. The formation of tumors in the eserine-treated animals correlated with the greater density of TEBs in the mammary gland present in 44-day-old treated animals (30). The concomitant increase in the area of ABs and lack of tumors in the control animals corroborated another studies (39). Our present data suggest that TEBs are major targets for chemical carcinogenesis in the rat mammary gland. This phenomenon was also seen in malathion- and parathiontreated rats before those structures were transformed in tumors (30). Eserine induced changes in the DNA synthesis of the rat submandibular gland after 5-day in vivo treatment, which confirmed the proliferative effect of this substance (28).

In the present study two mammary tumors were developed by the direct effect of $17 \mathrm{~B}$ estradiol in 12 rats injected at 39 days of age with a latency period of 180 and 245 days, respectively. Similarly to the case of DMBA-induced tumors the yield with eserine and estrogen treatment was only observed when the carcinogen was given to the rats at 39 days of age. The estrogen seems to act as an initiator in rat mammary cancer. The process of initiation occurred primarily in the epithelium of TEBs while such structures were developing into ABs. The chemical carcinogen DMBA in Sprague-Dawley rats $(12,39)$ induced mammary carcinomas in $100 \%$ of the animals with a latency period of 86 days. Others $(13,14)$ reported tumor formation with a single administration of NMU in mammary gland with similar latency. In contrast to these potent carcinogens, eserine and estrogen seem to have a slow and less infiltrating and potent effect. Eserine induced $8.6 \%$ of mammary gland tumors (30) whereas estrogen induced double the percentage of such tumors $(16 \%)$. The latency of eserine was 488 days whereas estrogen reduced such latency to half the time (212 days).

A number of agents have been shown to induce mammary carcinogenesis in rats and premalignant stages of the disease have been well characterized in chemically-induced models, specifically those initiated by either DMBA or NMU (40). In general, it appears that epithelial cells in mammary TEBs are the targets of carcinogenic initiation, and that a series of morphologically identifiable steps are involved in the development of mammary carcinoma. The premalignant steps include ductal hyperplasia of the usual type and carcinoma in situ of the cribiform or comedo type. Thus, the histogenesis of lesions occurring in eserine- and estrogeninduced mammary carcinogenesis in the rat is similar to that observed in the human.

There is an increasing body of experimental and clinical data supporting the involvement of estrogen on proliferation of hormone-dependent breast tumors. Estrogens play an important 
role in regulating the growth and differentiation of normal, premalignant and malignant cell types, especially breast epithelial cells (42), among them 173 estradiol is considered the primary mitogen for breast tissue (41). It has been reported that long-term exposure to estradiol increased the risk of breast cancer in a variety of animal species, as well as in women (43). In experimental animal models estrogens can induce mammary cancer (44). Estrogens can also mediate endothelial proliferation and differentiation and have been involved in estradiol-driven pathways of blood vessel assembly (45). Breast tumor tissue has also been shown to have an increased concentration of estradiol compared with serum levels (46).

It was previously reported that $17 \beta$ estradiol increased the growth fraction of mammary epithelial cells (the total compartments of the cells engaged in the cell cycle), DNA-LI, the length of $S$ phase and the total length of the cell cycle after 5 days in culture in comparison to the control (34). This hormone increased DNA synthesis, as shown by DNA-LI and $\left[{ }^{3} \mathrm{H}\right]$-thymidine incorporation into DNA in a 5-day organ culture, of fibrocystic disease lesions as well as carcinomas in situ of premenopausal women (29).

It can be concluded that eserine and estrogen play a crucial role in the cell proliferation and transformation of rat mammary gland by inducing the cell proliferation and then the formation of mammary tumors. This investigation of mammary gland susceptibility to an acetylcholinesterase inhibitor as well as estrogens, using a rat model, is important for understanding the biological and molecular characteristics of this disease.

\section{Acknowledgements}

We sincerely thank Sarah E. Baker and G. Cabello for their critical reading of the manuscript and Danissa Barahona for her administrative work. We also thank FONDECYT \# 1040300 (G.M.C).

\section{References}

1. Perera FP: Environment and cancer: who are susceptible? Science 278: 1068-1073, 1997.

2. Khan SA, Rogers MA, Khurana KK, Meguid MM and Numann PJ: Estrogen receptor expression in benign breast epithelium and breast cancer risk. J Natl Cancer Inst 90: 37-42, 1998.

3. MacMahon B, Cole P and Brown J: Etiology of human breast cancer: a review. J Natl Cancer Inst 50: 21-42, 1973.

4. MacMahon B, Trichopoulos D, Brown J, et al: Age menarche, urine estrogens and breast cancer risk. Int J Cancer 30: 427-431, 1982.

5. Peeters M, Verbeek AL, Krol A, Matthyssen MM and de Waard F: Age at menarche and breast cancer risk in nulliparous women. Breast Cancer Res Treat 33: 55-61, 1995.

6. Lathrop AE and Loeb L: Further investigations on the origin of tumors in mice. III. On the part played by internal secretion in the spontaneous development of tumors. J Cancer Res 1: 1-19, 1916.

7. Silman I and Futerman AH: Modes of attachment of acetylcholinesterase to the surface membrane. Eur J Biochem 170: 11-22, 1987.

8. Taylor P: Anticholinesterase agents. In: The Pharmacological Basis of Therapeutics. Goodman Gilman A, Rall TW, Nies AS and Taylor P (eds). Pergamon Press, New York, NY, pp131-147, 1990.

9. Klaasen C: Nonmetallic environmental toxicants: air pollutants, solvents and vapors, and pesticides. In: The Pharmacological Basis of Therapeutics. Goodman Gilman A, Rall TW, Nies AS and Taylor P (eds). Pergamon Press, New York, NY, pp1615-1635, 1990.
10. Russo J and Russo IH: DNA-labeling index and structure of the rat mammary gland as determinants of its susceptibility to carcinogenesis. J Natl Cancer Inst 61: 1451-1469, 1978.

11. Russo J and Russo IH: Influence of differentiation and cell kinetics on the susceptibility of the rat mammary gland to carcinogenesis. Cancer Res 40: 2677-2687, 1980.

12. Huggins $\mathrm{C}$ and Yang NC: Induction and extinction of mammary cancer. A striking effect of hydrocarbons permits analysis of mechanisms of causes and cure of breast cancer. Science 137: 257-262, 1962.

13. McCormick DL, Adamowski CB, Fiks A and Moon RC: Lifetime dose-response relationships for mammary tumor induction by a single administration of N-methyl-N-nitrosourea. Cancer Res 41: 1690-1694, 1981.

14. Gullino PM, Pettigrew HM and Grantham FH: N-nitrosomethylurea as mammary gland carcinogen in rats. J Natl Cancer Inst 54: 401-404, 1975.

15. Telang NT, Banarjee MR, Iyer AP and Kundu AB: Neoplastic transformation of epithelial cells in whole mammary gland in vitro. Proc Natl Acad Sci USA 76: 5886-5890, 1979.

16. Stampfer MR and Bartley JC: Induction of transformation and continuous cell lines from normal human mammary epithelial cells by exposure to benzo(a)pyrene. Proc Natl Acad Sci USA 82: 2394-2398, 1985.

17. Guzman RC, Osborn RC, Bartley JC, Imagawa W, Asch BB and Nandi $\mathrm{S}$ : In vitro transformation of mouse mammary epithelial cells grown serum free inside collagen gels. Cancer Res 47: 275-280, 1987.

18. Miyamoto S, Guzman RC, Osborn RC and Nandi S: Neoplastic transformation of mouse mammary epithelial cells by in vitro exposure to N-methyl-N-nitrosourea. Proc Natl Acad Sci USA 85: 477-481, 1988.

19. Thraves P, Salehi Z, Dritschilo A and Rhim JS: Neoplastic transformation of immortalized human epidermal keratinocytes by ionizing radiation. Proc Natl Acad Sci USA 87: 1174-1177, 1990.

20. Calaf $\mathrm{G}$ and Russo J: Transformation of human breast epithelial cells by chemical carcinogens. Carcinogenesis 14: 483-492, 1993.

21. Rhim JS and Dritschilo A: Neoplastic transformation in human cell systems - An overview. In: Neoplastic Transformation in Human Cell Culture: Mechanisms of Carcinogenesis. Rhim JS and Dritschilo A (eds). Totowa NJ Human Press, pp11-31, 1993.

22. Hei TK, Piao CQ, Willey JC, Sutter T and Hall EJ: Malignant transformation of human bronchial epithelial cells by radonsimulated $\alpha$ particles. Carcinogenesis 15: 431-437, 1994.

23. Riches AC, Herceg ZP, Bryant PE, Wynford-Thomas D: Radiation-induced transformation of SV40-immortalized human thyroid epithelial cells by single and fractionated exposure to girradiation in vitro. Int J Radiat Biol 66: 757-765, 1994.

24. Calaf G and Hei TK: Establishment of a radiation- and estrogeninduced breast cancer model. Carcinogenesis 21: 769-776, 2000.

25. Calaf G and Hei TK: Oncoprotein expressions in human breast epithelial cells transformed by high-LET radiation. Int J Radiat Biol 77: 31-40, 2001.

26. Stampfer M, Hallowes RC and Hackett J: Growth of normal human mammary cells in culture. In Vitro 16: 415-425, 1980.

27. Institute of Animal Laboratory Resources: Guide for the Care and Use of Laboratory Animals. Washington DC National Academy Press, 1996.

28. Calaf G, Garrido F and Cabello G: Effect of eserine treatment on DNA synthesis of rat submandibular gland. IRCS Med Sci 14: 343-344, 1986.

29. Calaf G, Garrido F, Moyano C and Rodriguez R: Influence of hormones on DNA synthesis of breast tumors in culture. Breast Cancer Res Treat 8: 223-232, 1986.

30. Cabello G, Valenzuela M, Vilaxa A, Duran V, Rudolph I, Hrepic $\mathrm{N}$ and Calaf G: A rat mammary gland tumor model induced by organophosphorous pesticides parathion and malathion, possibly through acetylcholinesterase inhibition. Environ Health Perspect 109: 471-479, 2001.

31. Russo J, Calaf G, Roi L and Russo I: Influence of age and gland topography on cell kinetics of normal human breast tissue. J Natl Cancer Inst 78: 413-418, 1987.

32. Calaf G, Martinez F, Russo IH and Russo J: The influence of age on DNA labeling index of human breast epithelium. Int Res Comm Syst Med 10: 657-658, 1982.

33. Calaf G, Martinez F, Russo IH and Russo J: Age-related variation in growth kinetics of primary human breast cell cultures. Int Res Comm Syst Med 10: 551-552, 1982. 
34. Calaf G, Russo IH, Roi L and Russo J: Effect of estrogen on the length of $\mathrm{S}$ phase phase of human breast tissue. Int Res Comm Syst Med 10: 307-308, 1982.

35. Calaf G, Russo IH, Roi L and Russo J: Effect of hormones on growth fraction of human breast tissue in organ culture. Int Res Comm Syst Med 10: 655-656, 1982.

36. Wanebo CK, Johnson KF, Sato K and Thorslund TW: Breast cancer after exposure to the atomic bombings of Hiroshima and Nagasaki. New Engl J Med 279: 667-671, 1968.

37. Barret JC and Ts'o POP: Relationship between somatic mutation and neoplastic transformation. Proc Natl Acad Sci USA 75: 3297-3301, 1978.

38. Kakunaga T: Neoplastic transformation of human diploid fibroblast cells by chemical carcinogens. Proc Natl Acad Sci USA 75: 1334-1388, 1978.

39. Russo J and Russo IH: Mammary tumorigenesis. In: Modification of Tumor Development in Rodents. Ito N and Sugano H (eds). Prog Exp Tumor Res, pp175-191, 1991.

40. Thompson HJ and Singh MJ: Rat models of premalignant breast disease. J Mammary Gland Biol Neoplasia 5: 409-420, 2000.

41. Dickson RB and Lippman ME: Estrogenic regulation of growth and polypeptide growth factor secretion in human breast carcinoma. Endocr Rev 8: 29-43, 1987.
42. Platet N, Cathiard AM, Gleizes M and Garcia M: Estrogens and their receptors in breast cancer progression: a dual role in cancer proliferation and invasion. Crit Rev Oncol Hematol 51: 55-67, 2004

43. Yue W, Santen RJ, Wang JP, et al: Genotoxic metabolites of estradiol in breast: potential mechanism of estradiol induced carcinogenesis. J Steroid Biochem Mol Biol 6: 477-486, 2003.

44. Shull JD, Spady TJ, Snyder MC, Johansson SL and Pennington KL: Ovary-intact, but not ovariectomized female ACI rats treated with 17beta-estradiol rapidly develop mammary carcinoma. Carcinogenesis 18: 1595-1601, 1997.

45. Soares R, Guo S, Gartner F, Schmitt FC and Russo J: 17ß estradiol-mediated vessel assembly and stabilization in tumor angiogenesis requires TGF $\alpha$ and EGFR crosstalk. Angiogenesis 6: $271-281,2003$

46. Masamura S, Santner SJ, Gimotty P, George J and Santen R: Mechanism for maintenance of high breast tumor estradiol concentrations in the absence of ovarian function: role of very high affinity tissue uptake. Breast Cancer Res Treat 42: 215-226, 1997. 